\title{
Are temporary anchorage devices truly effective in the treatment of skeletal open bites?
}

\author{
Hakan Turkkahraman ${ }^{1}$, Mehmet Sarioglu²
}

Correspondence: Dr. Hakan Turkkahraman

Email: hakanturkkahraman@sdu.edu.tr

\author{
'Department of Orthodontics, Faculty of Dentistry, \\ University of Suleyman Demirel, Isparta, Turkiye, \\ ${ }^{2}$ Private Practice, Izmir, Turkiye
}

\begin{abstract}
Objective: The aims of this study were to evaluate the effects of temporary anchorage devices (TADs) in the treatment of skeletal open bites and to compare the results with untreated controls. Materials and Methods: A total of forty patients with skeletal anterior open bites were assigned to two groups of twenty each. The mean chronological age for the treatment group (14 female, 6 male) was $16.68 \pm 2.80$ years old, compared with $16.63 \pm 2.83$ years old for the control group ( 11 female, 9 male). Titanium miniplates fixed bilaterally to the infrazygomatic crest area were used as TADs and intrusive forces were applied to the posterior teeth with Ni-Ti coil springs. The treatment and normal growth changes were evaluated using 24 measurements (2 angular, 22 linear). Results: Statistically significant differences were found between the groups in Bx, By, Sn/GoGn, Ax-Bx, U6x, U6y, overjet, overbite, SN/OccP, N-Me, Ans-Me, S-Go/N-Me, interpremolar width, and intermolar width $(P<0.05)$. In the treatment group, statistically significant upper molar intrusion (mean \pm standard deviation [SD], $3.59 \pm 1.34 ; 95 \%$ confidence interval [CI], 2.96-4.22), posterior rotation of the occlusal plane (mean $\pm \mathrm{SD}, 3.42 \pm 2.17 ; 95 \% \mathrm{CI}, 2.39-4.43$ ), anterior rotation of the mandible (mean $\pm \mathrm{SD}, 2.25 \pm 1.91 ; 95 \% \mathrm{CI}, 1.36-3.14$ ), and resultant overbite improvement (mean $\pm \mathrm{SD}, 4.82 \pm 1.53 ; 95 \%$ CI, 4.10-5.53) were found $(P<0.05)$. Conclusions: Mild to moderate skeletal anterior open bites could easily be treated with TADs without orthognathic surgery. With the rigid anchorage of miniplates, true molar intrusion of up to $4 \mathrm{~mm}$ was achieved. With molar intrusion, anterior rotation of the mandible and a significant reduction in anterior face height were determined.
\end{abstract}

Key words: Miniplates, molar intrusion, open bite treatment, temporary anchorage device

\section{INTRODUCTION}

Open bite is considered as a deviation in the vertical relationship of the maxillary and mandibular dental arches, characterized by a lack of contact between opposing segments of teeth. ${ }^{[1-3]}$ Open bite develops because of interaction of many etiologic factors, both hereditary and environmental in nature. ${ }^{[4]}$

Treatment of skeletal open bite is regarded as one of the most complicated and challenging treatments in the orthodontic specialty. Control of the vertical dimension and the height of the posterior dentoalveolar

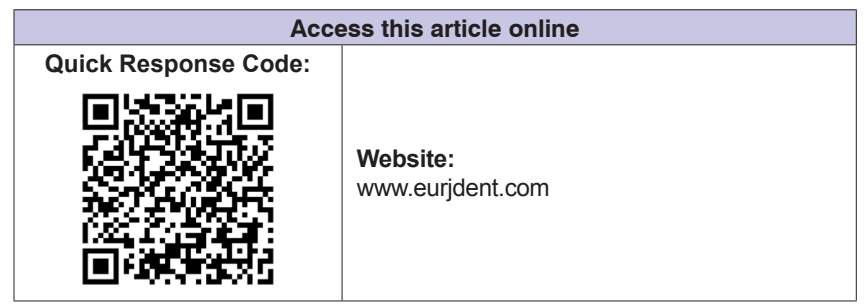

regions is considered the most important factor in successfully treating patients with skeletal open bite and hyperdivergency ${ }^{[5-10]}$ For the correction of anterior open bite with a steep mandible and excessive molar height, intrusion of the posterior teeth is generally the best option. ${ }^{[11]}$ However, intrusion of the molar teeth is quite difficult to obtain with traditional mechanics.

In recent years, temporary anchorage devices (TADs) have been increasingly used for skeletal open bite patients because they provide absolute molar

This is an open access article distributed under the terms of the Creative Commons Attribution-NonCommercial-ShareAlike 3.0 License, which allows others to remix, tweak, and build upon the work non-commercially, as long as the author is credited and the new creations are licensed under the identical terms.

For reprints contact: reprints@medknow.com

How to cite this article: Turkkahraman $\mathrm{H}$, Sarioglu M. Are temporary anchorage devices truly effective in the treatment of skeletal open bites?. Eur J Dent 2016;10:447-53.

DOI: $10.4103 / 1305-7456.195169$ 
intrusion, which used to be impossible with traditional orthodontic mechanics combined with intra- or extra-oral anchorage. ${ }^{[12-17]}$ Moreover, with the use of TADs, the vertical correction of the posterior dentoalveolar region without unfavorable side effects has become possible. ${ }^{[18]}$ The infrazygomatic crest has been used successfully to provide skeletal anchorage for the intrusion of the maxillary posterior teeth. ${ }^{[13,14,18-21]}$

On this subject, several case reports have already been published..$^{[14,15,20,22]}$ However, leading research articles have lacked sufficient sample sizes, ${ }^{[12,13,17,21,23,24]}$ some of them have lacked matched untreated controls, ${ }^{[13,21,25,26]}$ and some of them were retrospective, observational studies $^{[26]}$ and not randomized clinical trials. To the best of our knowledge, there have been no randomized, controlled trials evaluating the efficiency of TADs in the treatment of skeletal anterior open bites.

Therefore, the aims of the current study were to evaluate the effects of TADs in the treatment of skeletal open bites and to compare the results with untreated controls.

\section{MATERIALS AND METHODS}

This study was approved by the ethics committee of the Faculty of Medicine of Suleyman Demirel University. Written informed consent was provided by the patients and their parents before evaluation.

Required sample size for 0.90 power of the study was calculated with G*Power version 3.1.9.2. ${ }^{\left[{ }^{[2]}\right]}$ Three most affected variables (SN/GoGn, N-Me, and ANS-Me) were selected, and minimum required sample sizes were 12,22 , and 24 . We decided to begin the study with forty patients, and the achieved power was 0.99 .

Subjects meeting the following criteria were included in the study:

- No systemic disease

- No previous orthodontic treatment

- Permanent dentition stage

- Minimum of $2 \mathrm{~mm}$ of anterior open bite.

A total of forty patients were randomly assigned to two groups of twenty each. Each case is matched individually with a control according to age and gender. The mean chronological age for the treatment group (14 female, 6 male) was $16.68 \pm 2.80$ years old, compared to $16.63 \pm 2.83$ years old for the control group (11 female, 9 male) [Table 1]. The materials of this study consisted of eighty lateral cephalometric

\begin{tabular}{|c|c|c|c|}
\hline & \multicolumn{2}{|c|}{ Mean $\pm S D$} & \multirow[t]{2}{*}{$P$} \\
\hline & Treatment $(n=20)$ & Control $(n=20)$ & \\
\hline $\begin{array}{l}\text { Chronological } \\
\text { age (years) }\end{array}$ & $16.68 \pm 2.80$ & $16.63 \pm 2.83$ & 0.758 \\
\hline $\begin{array}{l}\text { Observation } \\
\text { period (years) }\end{array}$ & $1.00 \pm 0.31$ & $0.95 \pm 0.14$ & 0.565 \\
\hline $\mathrm{Ax}$ & $85.72 \pm 6.02$ & $88.70 \pm 5.15$ & 0.538 \\
\hline Ay & $67.36 \pm 3.38$ & $66.13 \pm 3.15$ & 0.549 \\
\hline $\mathrm{Bx}$ & $68.03 \pm 9.06$ & $72.73 \pm 8.25$ & 0.566 \\
\hline By & $109.62 \pm 5.59$ & $110.27 \pm 6.14$ & 0.876 \\
\hline SN/GoGn & $43.95 \pm 6.68$ & $40.59 \pm 4.76$ & 0.281 \\
\hline$A x-B x$ & $17.69 \pm 5.69$ & $15.98 \pm 5.14$ & 0.498 \\
\hline U1x & $53.05 \pm 3.78$ & $54.77 \pm 3.34$ & 0.576 \\
\hline U1y & $31.30 \pm 3.23$ & $31.71 \pm 3.89$ & 0.347 \\
\hline U6x & $20.08 \pm 3.15$ & $21.24 \pm 2.95$ & 0.941 \\
\hline U6y & $27.18 \pm 3.15$ & $28.00 \pm 3.26$ & 0.953 \\
\hline L1x & $65.62 \pm 4.72$ & $68.50 \pm 4.46$ & 0.885 \\
\hline L1y & $40.30 \pm 3.06$ & $41.71 \pm 3.68$ & 0.232 \\
\hline L6x & $41.38 \pm 3.16$ & $43.39 \pm 3.47$ & 0.745 \\
\hline L6y & $31.80 \pm 2.88$ & $33.41 \pm 3.39$ & 0.543 \\
\hline Overjet & $5.04 \pm 2.99$ & $4.93 \pm 2.76$ & 0.568 \\
\hline Overbite & $-4.34 \pm 1.71$ & $-4.63 \pm 1.42$ & 0.249 \\
\hline $\mathrm{SN} / \mathrm{OccP}$ & $19.69 \pm 4.67$ & $17.95 \pm 3.72$ & 0.640 \\
\hline $\mathrm{N}-\mathrm{Me}$ & $136.05 \pm 8.23$ & $137.09 \pm 8.87$ & 0.371 \\
\hline Ans-Me & $79.35 \pm 6.16$ & $81.01 \pm 7.91$ & 0.104 \\
\hline S-Go/N-Me & $57.05 \pm 4.04$ & $58.78 \pm 3.14$ & 0.314 \\
\hline Ls-E & $-3.45 \pm 3.24$ & $-3.16 \pm 2.07$ & 0.256 \\
\hline Li-E & $0.04 \pm 3.61$ & $0.65 \pm 2.48$ & 0.154 \\
\hline Interpremolar width & $37.54 \pm 2.71$ & $38.34 \pm 3.26$ & 0.259 \\
\hline Intermolar width & $49.24 \pm 2.39$ & $50.80 \pm 3.64$ & 0.078 \\
\hline
\end{tabular}

films and eighty dental casts obtained before (T1) and at the end of the treatment or of the observation period (T2). The mean observation period for the treatment group was $1.00 \pm 0.31$ years, compared to $0.95 \pm 0.14$ years for the control group [Table 1].

\section{Appliance design}

A rigid hyrax appliance was used to avoid unintentional buccal tipping of the posterior teeth by the intrusive forces. The bilateral arms of the appliance were soldered to the upper molar bands. The appliance was adapted at least $3 \mathrm{~mm}$ away from the palate [Figure 1].

A local anesthetic was infiltrated bilaterally at the zygomatic process areas. The surgical method, as previously described by Erverdi et al., ${ }^{[13,28]}$ was used. A $1 \mathrm{~cm}$ horizontal incision was madealong the zygomatic buttress and ending at the mucogingival junction. By means of blunt dissection, the zygomatic process of the maxilla was totally exposed. Three-hole titanium miniplates (Trimed, Ankara, Turkey) were adjusted to fit the contour of the infrazygomatic crest, and they were 


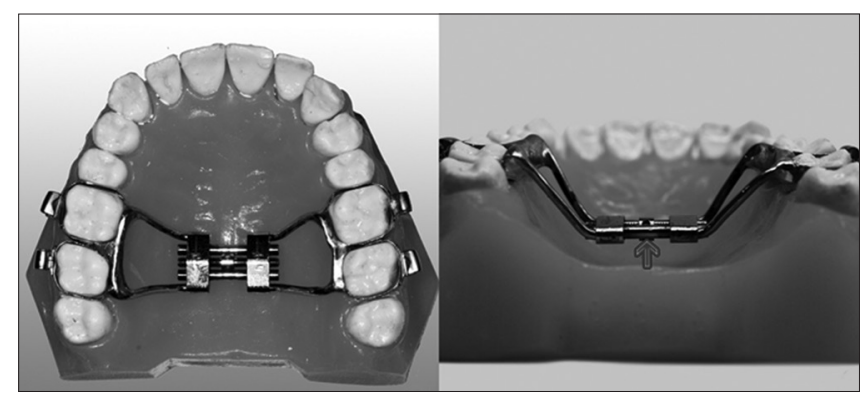

Figure 1: The transpalatal arch with hyrax screws used in the study

fixed with 7 and $9 \mathrm{~mm}$ screws (Trimed, Ankara, Turkey) [Figure 2]. The patients were advised and instructed how to brush and to rinse with $0.2 \%$ chlorhexidine.

Orthodontic brackets with 0.018 -inch slot size were bonded on the upper first and second premolar teeth and attached to the transpalatal arch (TPA) by $0.016 \times 0.022$-inch stainless steel partial arch wires. Nickel-titanium closed coil springs were used to deliver approximately $200 \mathrm{~g}$ of intrusive force from the miniplates to the posterior teeth.

\section{Cephalometric evaluation}

A total of 19 landmarks were identified on each cephalogram, and the treatment and normal growth changes between T1 and T2 were evaluated by 2 angular and 20 linear measurements, for a total of 22 measurements [Table 2]. All of the measurements were performed with Dolphin Imaging System (Dolphin Imaging and Management Solutions, Chatsworth, CA, USA).

The total and local structural superimposition method of Björk and Skieller ${ }^{[29]}$ was used to assess changes during the study period. A sella-nasion line was used as a horizontal reference line $(X)$ in the total structural superimposition. A perpendicular line passing through the sella was drawn to the horizontal axis. This perpendicular line was extended parallel $28 \mathrm{~mm}$ to the left, and all of the horizontal dimensional measurements were ensured to be positive values. This extended vertical line was used as a vertical reference line $(\mathrm{Y})$ [Figure 3].

The ANS-PNS line was used to evaluate the maxillary dentoalveolar changes according to their basal structures. The maxillary local superimposition was assessed at the PNS point. The ANS-PNS line was used as a horizontal reference line, and a perpendicular line passing through the PNS was drawn to the horizontal axis, which was used as a vertical reference line [Figure 4].

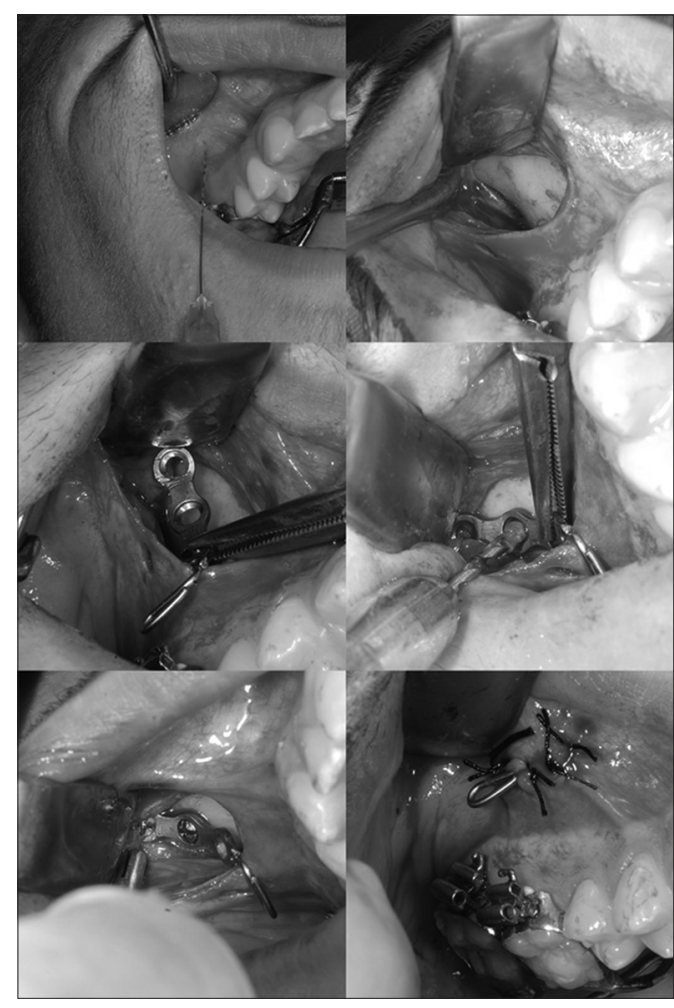

Figure 2: The steps of the surgical procedure

The Go-Gn line was used as a horizontal reference line in the mandibular local superimposition. A vertical reference line was drawn from the gonion perpendicular to the horizontal reference line [Figure 4].

The coordinate systems constructed on the first cephalogram (T1) were transferred to the second cephalogram (T2), and measurements were performed accordingly.

\section{Dental cast analysis}

Interpremolar and intermolar widths [Table 2] were measured on plaster models with digital calipers to the nearest $0.01 \mathrm{~mm}$.

\section{Statistical analysis}

All of the statistical analyses were performed using SPSS software, version 15.0 for Windows (SPSS Inc., Chicago, IL, USA). Intergroup comparisons were performed with independent samples of $t$-test. Statistical significance was determined at the $P<0.05$ level.

\section{RESULTS}

To calculate the method error of the study, twenty of the eighty lateral cephalometric films were selected 


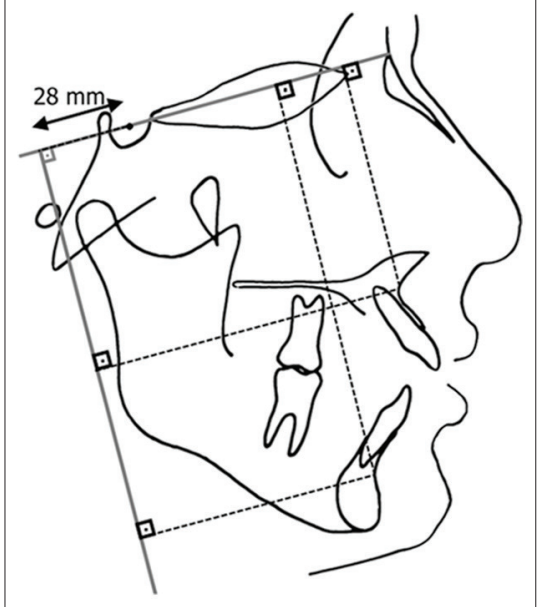

Figure 3: The total superimposition measurements

Table 2: Description of the linear and angular
measurements

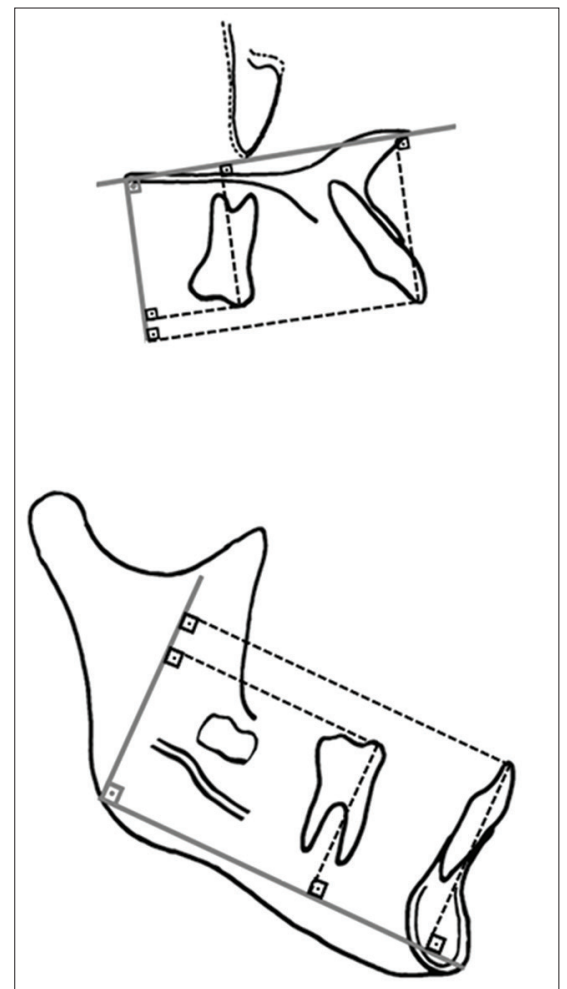

Figure 4: The maxillary and mandibular local superimposition measurements

randomly, and both the tracings and measurements were repeated. Repeatability coefficients were calculated with analysis of variance. The coefficients were found to be very close to 1.00 .

Statistical comparisons of the groups at $\mathrm{T} 1$ revealed no statistically significant differences in any of the measurements $(P>0.05)$. These results showed that the treatment and control groups were fully matched and almost identical [Table 1].

The statistical intergroup comparison of the differences of the measurements (T2-T1) is shown in Table 3. Statistically significant differences were found between the groups in Bx, By, Sn/GoGn, Ax-Bx, U6x, U6y, Overjet, Overbite, SN/OccP, N-Me, Ans-Me, $\mathrm{S}-\mathrm{Go} / \mathrm{N}-\mathrm{Me}$, Interpremolar width, and Intermolar width $(P<0.05)$.

In the treatment group, statistically significant upper molar intrusion (mean \pm standard deviation [SD], $3.59 \pm 1.34 ; 95 \%$ confidence interval [CI], 2.96-4.22), posterior rotation of the occlusal plane (mean \pm SD, $3.42 \pm 2.17 ; 95 \% \mathrm{CI}, 2.39-4.43)$, anterior rotation of the mandible (mean \pm SD, $2.25 \pm 1.91 ; 95 \%$ CI, 1.36-3.14). and resultant overbite improvement (mean $\pm \mathrm{SD}$, $4.82 \pm 1.53$; 95\% CI, 4.10-5.53) were found $(P<0.05)$. Significant reductions in total anterior (mean $\pm S D$, 


\begin{tabular}{|c|c|c|c|c|c|c|c|}
\hline & \multicolumn{6}{|c|}{ Mean士SD } & \multirow[t]{3}{*}{$P$} \\
\hline & \multicolumn{3}{|c|}{ Treatment $(n=20)$} & \multicolumn{3}{|c|}{ Control $(n=20)$} & \\
\hline & T1 & $\mathrm{T} 2$ & T2-T1 & T1 & $\mathrm{T} 2$ & T2-T1 & \\
\hline$\overline{A x}$ & $85.72 \pm 6.02$ & $86.03 \pm 4.69$ & $0.31 \pm 0.78$ & $88.70 \pm 5.15$ & $88.99 \pm 4.71$ & $0.29 \pm 1.54$ & 0.946 \\
\hline Ay & $67.36 \pm 3.38$ & $68.16 \pm 2.30$ & $0.81 \pm 0.82$ & $66.13 \pm 3.15$ & $67.16 \pm 2.19$ & $1.03 \pm 0.77$ & 0.383 \\
\hline$B x$ & $68.03 \pm 9.06$ & $71.07 \pm 7.01$ & $3.04 \pm 1.87$ & $72.73 \pm 8.25$ & $71.34 \pm 6.73$ & $-1.39 \pm 3.51$ & 0.000 \\
\hline By & $109.62 \pm 5.59$ & $106.52 \pm 4.22$ & $-3.10 \pm 1.81$ & $110.27 \pm 6.14$ & $111.63 \pm 5.16$ & $1.37 \pm 0.88$ & 0.000 \\
\hline SN/GoGn & $43.95 \pm 6.68$ & $41.70 \pm 5.42$ & $-2.25 \pm 1.91$ & $40.59 \pm 4.76$ & $41.05 \pm 3.93$ & $0.46 \pm 1.20$ & 0.000 \\
\hline$A x-B x$ & $17.69 \pm 5.69$ & $14.96 \pm 4.10$ & $-2.73 \pm 1.95$ & $15.98 \pm 5.14$ & $17.65 \pm 3.00$ & $1.67 \pm 3.96$ & 0.000 \\
\hline U1x & $53.05 \pm 3.78$ & $53.30 \pm 2.72$ & $0.25 \pm 0.48$ & $54.77 \pm 3.34$ & $55.06 \pm 2.49$ & $0.29 \pm 0.50$ & 0.763 \\
\hline U1y & $31.30 \pm 3.23$ & $31.60 \pm 2.30$ & $0.30 \pm 0.48$ & $31.71 \pm 3.89$ & $32.08 \pm 3.10$ & $0.37 \pm 0.37$ & 0.581 \\
\hline U6x & $20.08 \pm 3.15$ & $21.60 \pm 1.66$ & $1.52 \pm 1.28$ & $21.24 \pm 2.95$ & $21.27 \pm 1.93$ & $0.03 \pm 0.50$ & 0.000 \\
\hline U6y & $27.18 \pm 3.15$ & $23.59 \pm 1.73$ & $-3.59 \pm 1.34$ & $28.00 \pm 3.26$ & $28.51 \pm 2.33$ & $0.51 \pm 0.44$ & 0.000 \\
\hline L1x & $65.62 \pm 4.72$ & $65.64 \pm 3.76$ & $0.30 \pm 0.48$ & $68.50 \pm 4.46$ & $68.45 \pm 3.48$ & $0.37 \pm 0.37$ & 0.452 \\
\hline L1y & $40.30 \pm 3.06$ & $40.67 \pm 2.11$ & $0.03 \pm 0.36$ & $41.71 \pm 3.68$ & $42.14 \pm 2.84$ & $-0.06 \pm 0.33$ & 0.597 \\
\hline L6x & $41.38 \pm 3.16$ & $41.61 \pm 2.22$ & $0.23 \pm 0.42$ & $43.39 \pm 3.47$ & $43.35 \pm 2.57$ & $-0.04 \pm 0.47$ & 0.060 \\
\hline L6y & $31.80 \pm 2.88$ & $32.34 \pm 1.80$ & $0.54 \pm 0.37$ & $33.41 \pm 3.39$ & $33.75 \pm 2.46$ & $0.34 \pm 0.44$ & 0.087 \\
\hline Overjet & $5.04 \pm 2.99$ & $3.91 \pm 1.85$ & $-0.19 \pm 1.21$ & $4.93 \pm 2.76$ & $4.66 \pm 1.72$ & $0.77 \pm 1.44$ & 0.029 \\
\hline Overbite & $-4.34 \pm 1.71$ & $0.48 \pm 0.86$ & $4.82 \pm 1.53$ & $-4.63 \pm 1.42$ & $-4.54 \pm 12.50$ & $0.09 \pm 1.08$ & 0.000 \\
\hline SN/OccP & $19.69 \pm 4.67$ & $22.11 \pm 3.75$ & $3.42 \pm 2.17$ & $17.95 \pm 3.72$ & $17.48 \pm 2.56$ & $-0.47 \pm 1.32$ & 0.000 \\
\hline $\mathrm{N}-\mathrm{Me}$ & $136.05 \pm 8.23$ & $133.67 \pm 7.66$ & $-2.38 \pm 2.60$ & $137.09 \pm 8.87$ & $137.76 \pm 7.76$ & $0.67 \pm 1.41$ & 0.000 \\
\hline Ans-Me & $79.35 \pm 6.16$ & $76.05 \pm 4.58$ & $-3.30 \pm 1.68$ & $81.01 \pm 7.91$ & $81.62 \pm 6.73$ & $0.61 \pm 1.19$ & 0.000 \\
\hline S-Go/N-Me & $57.05 \pm 4.04$ & $58.27 \pm 3.24$ & $1.22 \pm 1.36$ & $58.78 \pm 3.14$ & $58.34 \pm 2.50$ & $-0.44 \pm 1.27$ & 0.000 \\
\hline Ls-E & $-3.45 \pm 3.24$ & $-4.20 \pm 2.85$ & $-0.75 \pm 1.87$ & $-3.16 \pm 2.07$ & $-2.96 \pm 1.04$ & $0.20 \pm 1.46$ & 0.082 \\
\hline Li-E & $0.04 \pm 3.61$ & $-0.65 \pm 3.27$ & $-0.69 \pm 1.90$ & $0.65 \pm 2.48$ & $0.58 \pm 1.80$ & $-0.08 \pm 1.56$ & 0.270 \\
\hline Interpremolar width & $37.54 \pm 2.71$ & $40.10 \pm 1.50$ & $2.56 \pm 1.93$ & $38.34 \pm 3.26$ & $38.60 \pm 2.22$ & $0.26 \pm 0.33$ & 0.000 \\
\hline Intermolar width & $49.24 \pm 2.39$ & $49.63 \pm 1.51$ & $0.39 \pm 0.6$ & $50.80 \pm 3.64$ & $50.82 \pm 2.46$ & $0.02 \pm 0.26$ & 0.015 \\
\hline
\end{tabular}

$2.38 \pm 2.60 ; 95 \% \mathrm{CI}, 1.16-3.60)$ and lower anterior face heights (mean $\pm \mathrm{SD}, 3.30 \pm 1.68 ; 95 \% \mathrm{CI}, 2.51-4.09$ ) were determined $(P<0.05)$.

\section{DISCUSSION}

TADs have opened up a new era in the management of severe dentofacial deformities, in which surgery had been the only option. With the successful intrusion of the maxillary molars, the mandible automatically rotates anteriorly, resulting in open-bite closure. A study by Umemori et al. ${ }^{[18]}$ first demonstrated the effective intrusion of mandibular molars when titanium miniplates were used for anchorage in humans. Later, Erverdi et al. ${ }^{[13,28]}$ suggested that the zygomatic buttress area was an ideal anchorage site for maxillary molar intrusion, and they reported the successful closure of anterior open bites.

In our study, the appliance and the mechanics successfully intruded the upper molars. We attained $3.59 \mathrm{~mm}$ of true molar intrusion. This amount of intrusion, to a large extent, was obtained by buccal intrusive forces. However, to a lesser extent, the TPAs might have contributed additional intermittent intrusive force of the tongue onto the molars. ${ }^{[30]}$ Similar amounts of molar intrusion have been reported in previous studies. . $12-14,20,21,26]^{2}$

Mesial movement of the molars by $1.52 \mathrm{~mm}$ was found in treatment group. As reported by Furst et al., ${ }^{[31]}$ infrazygomatic crest areas could be located in different mesiodistal positions in each individual. The location can cause some mesially directed forces acting on the molars, as well as mesial migration. Moreover, the location of the most proximal loop of the plate could also cause unfavorable mesiodistal angulation during the intrusion. ${ }^{[30]}$

After intrusion of the molars, autorotation of the mandible has been reported by several authors. ${ }^{[12-14,16-18,21,25,26]}$ This result was also true for our study because intrusion of the maxillary molars caused a significant anterior rotation of the mandible. The mandibular plane closed by an average of $2.25^{\circ}$, resulting in $3 \mathrm{~mm}$ of upward and forward movement of the chin. This distance is the desired movement because significant mandibular posterior rotation and accompanying increases in anterior face heights are common characteristics of skeletal open bites. Our 
results showed that a significant amount of reduction occurred in the lower anterior face height, resulting in a more balanced facial profile.

The significant amount of decrease in the Ax-Bx measurement revealed that the maxillary-mandibular skeletal base discrepancy was also treated with molar intrusion. This result was in agreement with the findings of previous studies. ${ }^{[13,14,16,17,21]}$ When molars are intruded, the mandible rotates anteriorly, and the chin prominence increases. Therefore, we suggest that molar intrusion using TADs could be very useful in treating Class II open bite cases with chin deficiency.

In the treatment of skeletal open bite, the most important treatment goal is to obtain a positive overbite. In our study, the net gain in overbite was $4.8 \mathrm{~mm}$, and this amount of correction was only attained by the intrusion of the maxillary molars. No extrusive forces were applied to the anterior teeth, which is very important because elongation of the anterior teeth provides unaesthetic results and leaves the skeletal component of the deformity unchanged. Moreover, the final overbite is not stable, even in the short term. Our results were in accordance with those of previous studies. ${ }^{[12-14,16,17,21,26]}$

When we evaluated transversal changes in maxillary arches, we noted small increases in the interpremolar and intermolar widths. The amount of expansion in the molar region was only $0.5 \mathrm{~mm}$, which is clinically insignificant. Çifter ${ }^{[32]}$ suggested using TPAs with two rigid arches to prevent vestibule inclination of the molar teeth during intrusion. Our appliance, strengthened with hyrax screws, maintained the transverse dimensions. Moreover, using hyrax screws provided the advantage that the orthodontist could counteract the buccal forces by reversely activating the screw if undesirable expansion occurred.

A limitation of the present study was the presenting of short-term results immediately after the intrusion stage. Posttreatment, postretention, and long-term follow-up are needed to determine clearly whether the results and obtained overbite were stable or not.

\section{CONCLUSIONS}

- Mild to moderate skeletal anterior open bites can be easily treated with TADs without orthognathic surgery

- With the rigid anchorage of miniplates, true molar intrusion of up to $4 \mathrm{~mm}$ was achieved
- With molar intrusion, anterior rotation of the mandible and significant reduction in anterior face heights were determined

- Rigid TPA with hyrax screws maintained the transverse dimension in the molar area.

\section{Acknowledgments}

We wish to thank Suleyman Demirel University, Scientific Researches Coordination Unit, for funding this project and Dr. Hikmet Orhan from Department of Zootechnics, Faculty of Agriculture of Suleyman Demirel University, for his help with statistical analyses.

\section{Financial support and sponsorship}

Nil.

\section{Conflicts of interest}

There are no conflicts of interest.

\section{REFERENCES}

1. Subtelny JD, Sakuda M. Open-bite: Diagnosis and treatment. Am J Orthod 1964;50:337-58.

2. Sassouni V, Nanda S. Analysis of dentofacial vertical proportions. Am J Orthod 1964;50:801-23.

3. Nanda SK. Patterns of vertical growth in the face. Am J Orthod Dentofacial Orthop 1988;93:103-16.

4. Cozza P, Baccetti T, Franchi L, Mucedero M. Comparison of 2 early treatment protocols for open-bite malocclusions. Am J Orthod Dentofacial Orthop 2007;132:743-7.

5. Schudy FF. Vertical growth versus anteroposterior growth as related to function and treatment. Angle Orthod 1964;34:75-93.

6. Björk A. Prediction of mandibular growth rotation. Am J Orthod 1969;55:585-99.

7. Nahoum HI. Anterior open-bite: A cephalometric analysis and suggested treatment procedures. Am J Orthod 1975;67:523-21.

8. Lavergne J, Gasson N. A metal implant study of mandibular rotation. Angle Orthod 1976;46:144-50.

9. Nielsen IL. Vertical malocclusions: Etiology, development, diagnosis and some aspects of treatment. Angle Orthod 1991;61:247-60.

10. English JD. Early treatment of skeletal open bite malocclusions. Am J Orthod Dentofacial Orthop 2002;121:563-5.

11. Ohmae M, Saito S, Morohashi T, Seki K, Qu H, Kanomi R, et al. A clinical and histological evaluation of titanium mini-implants as anchors for orthodontic intrusion in the beagle dog. Am J Orthod Dentofacial Orthop 2001;119:489-97.

12. Sherwood KH, Burch JG, Thompson WJ. Closing anterior open bites by intruding molars with titanium miniplate anchorage. Am J Orthod Dentofacial Orthop 2002;122:593-600.

13. Erverdi N, Keles A, Nanda R. The use of skeletal anchorage in open bite treatment: A cephalometric evaluation. Angle Orthod 2004;74:381-90.

14. Erverdi N, Usumez S, Solak A. New generation open-bite treatment with zygomatic anchorage. Angle Orthod 2006;76:519-26.

15. Park HS, Kwon OW, Sung JH. Nonextraction treatment of an open bite with microscrew implant anchorage. Am J Orthod Dentofacial Orthop 2006;130:391-402.

16. Xun C, Zeng X, Wang X. Microscrew anchorage in skeletal anterior open-bite treatment. Angle Orthod 2007;77:47-56.

17. Kuroda S, Sakai Y, Tamamura N, Deguchi T, Takano-Yamamoto T. Treatment of severe anterior open bite with skeletal anchorage in adults: Comparison with orthognathic surgery outcomes. Am J Orthod Dentofacial Orthop 2007;132:599-605.

18. Umemori M, Sugawara J, Mitani H, Nagasaka H, Kawamura H. Skeletal anchorage system for open-bite correction. Am J Orthod Dentofacial Orthop 1999;115:166-74. 
19. Liou EJ, Chen PH, Wang YC, Lin JC. A computed tomographic image study on the thickness of the infrazygomatic crest of the maxilla and its clinical implications for miniscrew insertion. Am J Orthod Dentofacial Orthop 2007;131:352-6.

20. Kuroda S, Katayama A, Takano-Yamamoto T. Severe anterior open-bite case treated using titanium screw anchorage. Angle Orthod 2004;74:558-67.

21. Erverdi N, Usumez S, Solak A, Koldas T. Noncompliance open-bite treatment with zygomatic anchorage. Angle Orthod 2007;77:986-90.

22. Park HS, Kwon TG, Kwon OW. Treatment of open bite with microscrew implant anchorage. Am J Orthod Dentofacial Orthop 2004;126:627-36.

23. Sugawara J, Baik UB, Umemori M, Takahashi I, Nagasaka H, Kawamura $\mathrm{H}$, et al. Treatment and posttreatment dentoalveolar changes following intrusion of mandibular molars with application of a skeletal anchorage system (SAS) for open bite correction. Int J Adult Orthodon Orthognath Surg 2002;17:243-53.

24. Baek MS, Choi YJ, Yu HS, Lee KJ, Kwak J, Park YC. Long-term stability of anterior open-bite treatment by intrusion of maxillary posterior teeth. Am J Orthod Dentofacial Orthop 2010;138:396.e1-9.

25. Akan S, Kocadereli I, Aktas A, Tasar F. Effects of maxillary molar intrusion with zygomatic anchorage on the stomatognathic system in anterior open bite patients. Eur J Orthod 2013;35:93-102.
26. Scheffler NR, Proffit WR, Phillips C. Outcomes and stability in patients with anterior open bite and long anterior face height treated with temporary anchorage devices and a maxillary intrusion splint. Am J Orthod Dentofacial Orthop 2014;146:594-602.

27. Faul F, Erdfelder E, Lang AG, Buchner A. G*Power 3: A flexible statistical power analysis program for the social, behavioral, and biomedical sciences. Behav Res Methods 2007;39:175-91.

28. Erverdi N, Tosun T, Keles A. A new anchorage site for the treatment of anterior open bite: Zygomatic anchorage case report. World J Orthod 2002;3:147-53.

29. Björk A, Skieller V. Normal and abnormal growth of the mandible. A synthesis of longitudinal cephalometric implant studies over a period of 25 years. Eur J Orthod 1983;5:1-46.

30. Seres L, Kocsis A. Closure of severe skeletal anterior open bite with zygomatic anchorage. J Craniofac Surg 2009;20:478-82.

31. Furst IM, Austin P, Pharoah M, Mahoney J. The use of computed tomography to define zygomatic complex position. J Oral Maxillofac Surg 2001;59:647-54.

32. Çifter M. Üst Çene Posterior Dişlerinin Mikro-Implant Destekli Intrüzyonunda Meydana Gelen Değişikliklerin Sonlu Elemanlar Analizi ile Incelenmesi. Istanbul: Istanbul Universitesi Sağlık Bilimleri Enstitüsü Ortodonti Anabilim Dalı, Istanbul Universitesi; 2007 